\title{
Sobre el estatuto técnico y político de la obra de arte en Hannah Arendt y Giorgio Agamben
}

\section{ON THE TECHNICAL AND POLITICAL STATUS OF THE WORK OF ART IN HANNAH ARENDT AND GIORGIO AGAMBEN}

Carlos Eduardo Quenaya Mendoza

Universidad de Lima

cquenaya@ulima.edu.pe

\section{RESUMEN}

Luego de revisar el significado de conceptos como poíesis y praxis, examinamos la distinción arendtiana entre labor, trabajo y acción, que recoge la herencia griega y sitúa en su interior su reflexión personal sobre la obra de arte. Enseguida, desarrollamos las intuiciones de un joven Agamben, quien en un ensayo publicado en su primer libro argumenta que es el concepto de poíesis el que en el curso de la modernidad habría sido ofuscado por la praxis. Por último, intentamos complementar las perspectivas de ambos filósofos a partir de la pregunta por el estatuto político del arte y su dimensión técnica PALABRAS CLAVE: obra de arte, potencia, política, producción, acción

\section{ABSTRACT}

After reviewing the meaning of concepts such as poiesis and praxis, we examined the Arendtian distinction between labor, work, and action, which rekindles the Greek heritage and places within it Arendt's reflection on the work of art. Next, we develop the intuitions of a young Agamben, who, in an essay published in his first book, arguea that it is the concept of poiesis that, in the course of modernity, would have been obfuscated by praxis. Finally, we try to complement the perspectives of both philosophers questioning the political status of art and its technical dimension.

KEYWORDS: work of art, power, politics, production, action 


\section{POÍESIS Y PRAXIS}

En griego, la palabra poíesis' significa tanto "creación" y "producción", en un sentido general, como "poesía", en un sentido más específico; y lo mismo poietés, que puede traducirse como "creador o poeta"2. Agamben (2005) contrasta el significado de ambos conceptos relacionando poíesis con poiein 'producir', en el sentido de llevar a ser, y praxis con prattein 'hacer', en el sentido de realizar (p. 112). Asimismo, el filósofo italiano recuerda que el término techné designaba unitariamente tanto la actividad del artesano que da forma a un jarrón o a un utensilio, como la del artista que plasma una estatua o escribe un poema (p. 99). Los objetos producidos a través del arte son susceptibles de ser o no ser; es decir, son contingentes, no necesarios. Su principio, además, no descansa en el objeto producido, sino en quien lo produce, lo que distingue a los objetos hechos por las manos humanas de los objetos naturales que tienen en sí el principio del movimiento ${ }^{3}$. El artista produce, no actúa, a diferencia del político, que actúa, pero no produce:

Porque el fin de la producción es distinto de ella, pero el de la acción no puede serlo pues una acción bien hecha es ella misma el fin. Por eso creemos que Pericles y otros como él son prudentes, porque pueden ver lo que es bueno para ellos y para los hombres, y pensamos que esta es una cualidad propia de los administradores y de los políticos. (Ética a Nicómaco, VI, 5, 1140b)

La racionalidad productiva es una forma de racionalidad instrumental, pues la actividad del artista no es un fin en sí mismo, sino un medio con vistas al objeto producido. La racionalidad práctica, en cambio, tiene un carácter fútil: la acción ética y política es ella misma un fin; esto es, no deja nada tras de sí. No son identificables las actividades de un político como Pericles y un pintor como Polignoto. La teoría de la ciencia de Aristóteles presupone la distinción de conceptos como poíesis y praxis. Para el estagirita, distinguir

1 Para una mirada de la evolución del concepto de poíesis, es recomendable el libro El concepto "poíesis" en la filosofía griega (1961), de Emilio Lledó.

2 Vale la pena tener en cuenta las precisiones de Platón: “Tú sabes que la idea de 'creación' (poíesis) es algo múltiple, pues en realidad toda causa que haga pasar cualquier cosa del no ser al ser es creación, de suerte que también los trabajos realizados en todas las artes son creaciones y los artífices son todos creadores (poietaí). [...] Pero también sabes - continuó ella-que no se llaman creadores, sino que tienen otros nombres y que del conjunto entero de creación se ha separado una parte, la concerniente a la música y al verso, y se le denomina con el nombre del todo. Únicamente a esto se llama, en efecto, poesía, y poetas a los que poseen esta porción de creación" (Banquete, 205c).

3 Tal como leemos en la Física: "Algunas cosas son por naturaleza, otras por otras causas. Por naturaleza, los animales y sus partes, las plantas y los cuerpos simples como la tierra, el fuego, el aire y el agua [...]. Todas estas cosas parecen diferenciarse de las que no están constituidas por naturaleza, porque cada una de ellas tiene en sí misma un principio de movimiento y reposo, sea con respecto al lugar o al aumento o a la disminución o a la alteración. Por el contrario, una cama, una prenda de vestir o cualquier otra cosa de género semejante, en cuanto que las significamos en cada caso por su nombre y en tanto que son productos de arte, no tienen en sí mismas ninguna tendencia natural al cambio; pero en cuanto que, accidentalmente, está hecha de piedra o de tierra o de una mezcla de ella, y solo bajo este respecto, la tienen" (Física, II, 192b). 
el conocimiento productivo (poiético) del práctico es de particular importancia para delimitar el campo de la ética y del arte:

La producción es distinta de la acción [...]; de modo que también el modo de ser racional práctico es distinto del modo de ser racional productivo. Por ello, ambas se excluyen recíprocamente, porque ni la acción es producción ni la producción es acción. [...] Todo arte versa sobre la génesis, y practicar un arte es considerar cómo puede producirse algo de lo que es susceptible tanto de ser como de no ser y cuyo principio está en quien lo produce y no en lo producido. En efecto, no hay arte de cosas que son o llegan a ser por necesidad, ni de cosas que se producen de acuerdo con su naturaleza, pues estas tienen su principio en sí mismas. Dado que la producción y la acción son diferentes, necesariamente el arte tiene que referirse a la producción y no a la acción. (Ética a Nicómaco, VI, 4, 1140a)

La alta estima de la acción por sobre las actividades productivas, así como por sobre las actividades relacionadas con el mantenimiento de la vida, propias del esclavo, tiene una historia llena de tensiones y contraposiciones. Una de ellas aparece con el nacimiento de la filosofía. El filósofo reclama para sí la actividad más eminente: la teórica, señaladamente apolítica. Sin embargo, es en el curso de la modernidad cuando se invierten los papeles y la categoría de acción comienza a entenderse a partir de las actividades ligadas a la fabricación y a la vida biológica. Lo que Arendt describe en La condición humana (1996) como el ascenso de la labor.

\section{EL HOMO FABER Y LA OBRA DE ARTE}

En palabras de Arendt (1996):

Labor es la actividad correspondiente al proceso biológico del cuerpo humano, cuyo espontáneo crecimiento, metabolismo y decadencia final están ligados a las necesidades vitales producidas y alimentadas por la labor en el proceso de la vida. La condición humana de la labor es la misma vida. (p. 22)

Estas actividades, en la Grecia clásica, son realizadas por los esclavos dentro de la esfera privada. Son actividades indispensables para el mantenimiento cotidiano de la vida y tienen un carácter cíclico y repetitivo. Corresponden al reino de la necesidad y su satisfacción es una condición para acceder a la esfera pública, que es el espacio privilegiado de la acción y la libertad.

Entre la labor y la acción se encuentran las actividades relacionadas con el trabajo, que Arendt (1996) identifica con las actividades propias del homo faber (hombre fabricante de utensilios). Trabajo es la actividad que corresponde a lo no natural de la existencia humana y que no está inmerso en el repetido ciclo vital de la especie. El trabajo proporciona un artificial mundo de cosas. La condición humana del trabajo es la mundanidad (p. 22). El trabajo está relacionado con la producción de objetos útiles. El trabajo, gracias 
al cual se produce un mundo artificial de cosas, es el que posibilita un hogar dentro del mundo para los hombres. Este mundo de objetos confiere cierto grado de estabilidad a los asuntos humanos. Los productos de la labor aparecen y desaparecen incesantemente mientras dure nuestro ciclo vital. En cambio, los productos del trabajo aspiran a tener una relativa permanencia y a constituir un mundo humano. Arendt incluye dentro de esta categoría a las obras de arte. En La condición humana (1996), en el capítulo sobre el trabajo, la sección 23 está explícitamente dedicada a pensar los objetos del arte y la cultura:

Debido a su sobresaliente permanencia, las obras de arte son las más intensamente mundanas de todas las cosas tangibles; su carácter duradero queda casi inalterado por los corrosivos efectos de los procesos naturales, puesto que no están sujetas al uso por las criaturas vivientes [...]. En ningún otro sitio aparece con tanta pureza y claridad el carácter duradero del mundo de las cosas, en ningún otro sitio, por lo tanto, se revela este mundo de cosas de modo tan espectacular como el hogar no mortal para los seres mortales. Es como si la estabilidad mundana se hubiera hecho transparente en la permanencia del arte, de manera que una premonición de inmortalidad, no la inmortalidad del alma o de la vida, sino de algo inmortal realizado por manos mortales, ha pasado a ser tangiblemente presente para brillar y ser visto, para resonar y ser oído, para hablar y ser leído. (p. 185)

El concepto arendtiano de trabajo abarca las actividades de la poíesis, que precisamente incluían la actividad de fabricar utensilios y la elaboración de obras artísticas. El trabajo de nuestras manos, a diferencia de la labor de nuestro cuerpo, alcanza el grado más alto de mundanidad en las obras de arte. Sin ser objetos de uso, los objetos de la cultura -en cuanto objetos bellos- están hechos para su contemplación. A diferencia del entretenimiento que producen los objetos de consumo, que constantemente deben renovarse a causa de su rápida caducidad, las obras de arte no se consumen: el arte demanda nuestro juicio estético, facultad constantemente desafiada por la radical singularidad de los objetos artísticos.

A partir de las distinciones entre labor, trabajo y acción, Arendt entiende la historia política de Occidente como un progresivo ascenso de la labor y la consecuente disolución de la esfera pública y la privada, lo que dará lugar al auge de lo social. Vistas las cosas así, las actividades prácticas se entenderán principalmente desde la perspectiva de la labor, lo que significa que la política se subordinará a la economía y a las actividades relacionadas con el mantenimiento de la vida.

En lo que respecta al estatuto moderno de la obra de arte, Agamben (2005) -en un ensayo de su primer libro- explica la distinción que separa los objetos originalmente incluidos dentro del concepto de poíesis:

En efecto, con el desarrollo de la técnica moderna a partir de la primera revolución industrial en la segunda mitad del siglo xvIII y con el afirmarse de una cada vez más 
extendida y alienante división del trabajo, la condición, la forma de la presencia de las cosas producidas por el hombre se vuelve doble: a un lado están las cosas que entran en la presencia según el estatuto de la estética, es decir, las obras de arte, y al otro las que llegan a ser según el estatuto de la técnica, esto es, los productos en sentido estricto. (pp. 99-100)

Los objetos estéticos, a partir del horizonte moderno, quedan separados así de los productos de la técnica:

La experiencia central de la poíesis, la producción hacia la presencia, cede ahora su sitio a la consideración del "cómo", o sea, del proceso a través del que se ha producido el objeto. Por lo que respecta a la obra de arte, esto significa que el acento se desplaza de la que para los griegos era la esencia de la obra, es decir, el hecho de que algo en ella llegase al ser desde el no-ser, abriendo así el espacio de la verdad (aletheia) y edificando un mundo para el habitar del hombre sobre la tierra, al operari del artista, esto es, al genio creativo y a las particulares características del proceso artístico en las que encuentra expresión. (Agamben, 2005, p. 114)

Esto quiere decir que la obra de arte desplaza su carácter mundano; esto es, deja de ser un objeto del mundo y se convierte en una actividad del artista, un producto de su voluntad: "El punto de llegada de la estética occidental es una metafísica de la voluntad, es decir, de la vida entendida como energía e impulso creador" (Agamben, 2005, p. 117). El centro de la atención estética se desplaza del mundo al yo. La poíesis en la que se inscribe la obra de arte griega la sitúa dentro del marco mayor de los objetos que constituyen el mundo como un lugar hecho con nuestras manos:

La esencia de la poíesis no tenía nada que ver con la expresión de una voluntad (con respecto a la cual el arte no es necesario de ningún modo); esa esencia, en cambio, reside en la producción de la verdad y en la consiguiente apertura de un mundo para la existencia y la acción del hombre. (Agamben, 2005, p. 117)

El valor de la obra de arte y su carácter duradero no se basaba en el hecho de ser la expresión de un genio, sino en su intensa mundanidad. Al no ser objetos de uso, las obras de arte reclamaban ser vistas y ser oídas, ser dichas y ser leídas. Tanto los objetos producto del trabajo como las obras del artista constituyen un mundo donde es posible la acción política. La acción, entendida como el aventurarse en el discurso y en el actuar en compañía de los que son iguales a uno, solo es posible en un mundo común abierto por el homo faber.

De acuerdo con Agamben (2005), la ruptura moderna entre los objetos bellos y los objetos producidos por la técnica abre nuevas dicotomías:

La reproductibilidad (entendida en este sentido como relación paradigmática, de no-proximidad con el origen) es, por tanto, la condición esencial del producto de la técnica, así como la originalidad (o autenticidad) es la condición esencial de la obra de arte. (p. 101) 
Los objetos producto de la técnica son reproducibles y, por lo tanto, carecen de originalidad. Los objetos artísticos, productos del genio, son irreproducibles y, en consecuencia, se revelan como originales. Estas coordenadas entrarán en crisis a partir de lo que Walter Benjamin describirá como la pérdida del aura. En efecto, las categorías tradicionales de comprensión de la obra de arte - tales como genio, autenticidad y misterio- cederán su lugar frente al progreso de la técnica:

Conforme a una formulación general, podemos decir que la reproducción técnica desvincula lo reproducido del ámbito de la tradición. Al multiplicar las reproducciones, pone su presencia masiva en el lugar de una presencia irrepetible. $Y$ al permitirle a la reproducción salir al encuentro de cada destinatario, se encuentre donde se encuentre, hace que lo reproducido se actualice siempre. (Benjamin, 2018, p. 199)

Si la estética moderna está comprometida con una metafísica de la voluntad, según la tesis de Agamben (2005), ¿de qué forma puede ser repensada a la luz de la crítica de la metafísica del sujeto?, ¿qué relación habría entre la pérdida del aura de la obra de arte y el ofuscamiento de la distinción entre poíesis y praxis? En palabras de Agamben (2005), "la pregunta sobre el destino del arte suena de esta forma: ¿cómo es posible acceder de manera original a una nueva poíesis?" (p. 105).

\section{UNA NUEVA POÍESIS: LA POTENCIA DE NO}

De la aproximación de las reflexiones estéticas y políticas de Arendt y Agamben se puede inferir que el desplazamiento moderno del mundo al sujeto tiene como consecuencia la progresiva "desmundanización" de la obra de arte. El deterioro de la esfera pública y del espacio común donde aparecen las obras -y la consiguiente reclusión de la experiencia estética al ámbito personal-sería una forma de despolitización de la poíesis, por lo que sería posible decir - siguiendo la lectura de Agamben - que la obra de arte se despolitiza cuando se subordina a la praxis, es decir, a la voluntad del sujeto. De modo que surge así el problema de restablecer el vínculo entre la dimensión productiva y política del arte: ¿cómo es posible pensar una nueva poíesis?

Agamben se ha planteado este problema en numerosos ensayos. La pregunta por el acto de creación, entendido como un acto poético en el sentido más amplio, es abordada a través del concepto de potencia (dynamis). El acto de creación tiene una relación constitutiva con la liberación de una potencia (Agamben, 2016, p. 37). Así, el autor italiano recuerda: "Dýnamis, potencia [...], significa tanto potencia como posibilidad, y ambos significados no deberían estar nunca separados" (Agamben, 2008, p. 354).

El concepto de potencia tiene una historia que se remonta a Aristóteles. La potencia no solo consistiría en la facultad de actualizar lo que estaba latente. La potencia supone 
también la potencia de no. Agamben (2008) distingue entre la potencia genérica y la potencia como "tener una privación":

El niño, escribe Aristóteles, es potente en el sentido de que deberá sufrir una alteración por el aprendizaje; quien ya posee una técnica, en cambio, no debe sufrir alteración alguna, sino que es potente a partir de una héxis, que puede no poner en acto, o bien actuar, pasando de un no ser en acto a un ser en acto [...]. La potencia es definida, así, esencialmente por la posibilidad de su no-ejercicio. (pp. 355-356)

Esto significa que toda potencia es impotencia: potencia de ser y no ser, de hacer y no hacer. La potencia subsiste con el carácter de la contingencia. La potencia humana -el yo puedo-supone necesariamente la potencia de no - el yo no puedo-:

Podemos decir entonces que el hombre es el viviente que existe en modo eminente en la dimensión de la potencia, del poder y del poder no. Toda potencia humana es, cooriginariamente, impotencia; todo poder-ser o poder-hacer está, para el hombre, constitutivamente en relación con la propia privación. Y este es el origen de la desmesura de la potencia humana, tanto más violenta y eficaz respecto de la de los otros seres vivientes. Los otros vivientes pueden solo su potencia específica, pueden solo este o aquel comportamiento inscrito en su vocación biológica; el hombre es el animal que puede la propia impotencia. La grandeza de su potencia se mide por el abismo de su impotencia. (Agamben, 2008, p. 362)

Esta ambigüedad de la potencia se manifiesta plenamente en la obra de arte. A diferencia de los objetos útiles, las obras de arte nunca terminan de actualizarse, nunca terminan de ser, pues mantienen dentro de sí la potencia de no:

La praxis propiamente humana es aquella que, volviendo inoperosas las obras y las funciones específicas del viviente, las hace, por así decir, girar en el vacío $y$, de esta forma, las abre a la posibilidad. Contemplación e inoperosidad son, en este sentido, los operadores metafísicos de la antropogénesis que, liberando al viviente humano de todo destino biológico o social y de toda tarea predeterminada, lo vuelven disponible para esa particular ausencia de obra que estamos acostumbrados a llamar política y arte. (Agamben, 2016, pp. 48-49)

La acción política, en tanto que no tiene como resultado la producción de obras, requiere la asistencia del homo faber, pues como sabía Arendt (1996):

Si el animal laborans necesita la ayuda del homo faber para facilitar su labor y aliviar su esfuerzo, y si los mortales necesitan su ayuda para erigir un hogar en la Tierra, los hombres que actúan y hablan necesitan la ayuda del homo faber en su más elevada capacidad, esto es, la ayuda del artista, de poetas e historiógrafos, de constructores de monumentos o de escritores, ya que sin ellos el único producto de su actividad, la historia que establecen y cuentan, no sobreviviría. Con el fin de que el mundo sea lo que siempre se ha considerado que era, un hogar para los hombres durante su vida en la Tierra, el artificio humano ha de ser lugar apropiado para la acción y el discurso. (p. 191) 
Esto significa que el arte, al abrir posibilidad, crea condiciones para que el mundo siga siendo un hogar en el que los hombres hablen y actúen. La tarea política del arte es abrir posibilidad, en la medida en que la acción política implica la capacidad de empezar algo nuevo. Pero esta tarea no es una que subordine el arte a la acción política, la poíesis a la praxis 0 , dicho de otra manera, la imaginación a la realidad. El arte, pensado fuera de las viejas categorías de la metafísica de la voluntad a la que alude Agamben, asume su función política cuando se plantea la pregunta por la técnica artística, no por el contenido. El autor, entendido ya no como genio, sino como productor, es el que considera la obra de arte en cuanto técnica. De ahí que la pregunta política más importante para el artista no sea qué es el arte, sino más bien qué será. En no saber y, sin embargo, seguir ensayando respuestas radica su singular potencia.

\section{REFERENCIAS}

Agamben, G. (2005). El hombre sin contenido. Ediciones Áltera.

Agamben, G. (2008). La potencia del pensamiento. Anagrama.

Agamben, G. (2016). El fuego y el relato. Sexto Piso.

Arendt, H. (1996). La condición humana. Paidós Ibérica.

Aristóteles. (1985). Ética nicomaquea. Ética eudemia. Gredos.

Aristóteles. (1998). Física. Gredos.

Benjamin, W. (2018). Iluminaciones. Taurus.

Lledó, E. (1961). El concepto "poíesis" en la filosofía griega. Consejo Superior de Investigaciones Científicas.

Platón. (1988). Diálogos III. Fedón, Banquete, Fedro. Gredos. 